\title{
Near-future levels of ocean acidification do not affect sperm motility and fertilization kinetics in the oyster Crassostrea gigas
}

\author{
J. N. Havenhand and P. Schlegel \\ Department of Marine Ecology - Tjärnö, University of Gothenburg, Tjärnö, 45296 Strömstad, Sweden
}

Received: 26 March 2009 - Published in Biogeosciences Discuss.: 30 April 2009

Revised: 30 November 2009 - Accepted: 7 December 2009 - Published: 15 December 2009

\begin{abstract}
An increasing number of studies are now reporting the effects of ocean acidification on a broad range of marine species, processes and systems. Many of these are investigating the sensitive early life-history stages that several major reviews have highlighted as being potentially most susceptible to ocean acidification. Nonetheless there remain few investigations of the effects of ocean acidification on the very earliest, and critical, process of fertilization, and still fewer that have investigated levels of ocean acidification relevant for the coming century. Here we report the effects of nearfuture levels of ocean acidification $(\approx-0.35 \mathrm{pH}$ unit change) on sperm swimming speed, sperm motility, and fertilization kinetics in a population of the Pacific oyster Crassostrea gigas from western Sweden. We found no significant effect of ocean acidification - a result that was well-supported by power analysis. Similar findings from Japan suggest that this may be a globally robust result, and we emphasise the need for experiments on multiple populations from throughout a species' range. We also discuss the importance of sound experimental design and power analysis in meaningful interpretation of non-significant results.
\end{abstract}

\section{Introduction}

It is now accepted that increasing atmospheric $\mathrm{CO}_{2}$ is causing reductions in oceanic $\mathrm{pH}-\mathrm{a}$ process widely referred to as "ocean acidification". Global ocean $\mathrm{pH}$ has fallen by an average of $0.1 \mathrm{pH}$ units since the onset of the industrial revolution and several estimates show that oceanic $\mathrm{pH}$ could fall additionally by $\leq 0.4 \mathrm{pH}$ units by the year 2100 (Caldeira and Wickett, 2003; Raven et al., 2005; Blackford and Gilbert,

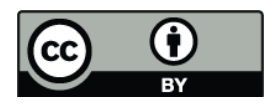

Correspondence to: J. N. Havenhand (jon.havenhand@marecol.gu.se)
2007; IPCC, 2007). This results in decreases in the saturation states of calcite and aragonite, the two common crystalline forms of biogenic $\mathrm{CaCO}_{3}$. Estimates of future rates of reduction in saturation states vary, but it has been predicted that high latitude oceans will become undersaturated with respect to aragonite (the more soluble of the two forms) by the year 2050 (Orr et al., 2005). Extensive field observations from the US west coast have already found seasonal upwelling of undersaturated waters reaching the surface (Feely et al., 2008). The extent of this process in other parts of the world is currently unknown.

The biological consequences of these changes have been reported in several recent studies (see reviews by Harley et al., 2006; Fabry et al., 2008; Widdicombe and Spicer, 2008; Doney et al., 2009). These studies show that if ocean $\mathrm{pH}$ does fall by a further 0.4 units, there will likely be substantial negative effects on calcification and physiological processes in a wide variety of species and ecosystems. These effects are particularly relevant to the very earliest life-history stages of marine invertebrates, fertilization, embryogenesis and larval development, which are not only often the most sensitive life-stages to environmental change, but which are also key for the successful recruitment - and hence survival - of the species (Pechenik, 1999; Cowen et al., 2000; Raven et al., 2005).

Many workers have investigated the impacts of mineral acids on gametes and fertilization in marine invertebrates, but the effects of these acids are very different to those of $\mathrm{CO}_{2}$-induced acidification (Kurihara and Shirayama, 2004; Kurihara, 2008). Relatively few studies have investigated the impacts of $\mathrm{CO}_{2}$-induced changes in $\mathrm{pH}$ on fertilization (reviewed by Kurihara, 2008). Kurihara and Shirayama (2004) studied the sea urchins Hemicentrotus pulcherrimus and Echinometra mathaei finding that fertilization success declined with $\mathrm{pH}$, and was statistically significant at $5000 \mathrm{ppm} \mathrm{CO}_{2}(\approx \mathrm{pH} \leq 7.1)$. Havenhand

Published by Copernicus Publications on behalf of the European Geosciences Union. 
et al. (2008) studying the urchin Heliocidaris erythrogramma found statistically significant reductions in fertilization success at pH $7.7\left(\approx 1000 \mathrm{ppm} \mathrm{CO}_{2}\right)$. Lastly, Kurihara et al. (2007, 2009) found no significant effect of $2000 \mathrm{ppm} \mathrm{CO}_{2}$ $(\approx \mathrm{pH} 7.4)$ treatments on fertilization success of the bivalves Crassostrea gigas and Mytilus galloprovincialis from Japan (although there were significant subsequent effects on larval development - see below).

Substantial intraspecific variation in response of fertilization success to ocean acidification was also found by Kurihara and Shirayama (2004), perhaps indicating the capacity for heritable variation within populations (Kurihara, 2008). Variable fertlization success can be a result of variable gamete quality, but is more commonly a natural consequence of differential compatibilities of male and female gametes: put simply, some gametes are more compatible and fertilize more easily at a given sperm concentration (e.g. Styan et al., 2008). Compatibility is most easily determined using fertilization kinetics curves, which fit a first-principles model of fertilization kinetics to fertilization success data from multiple sperm concentrations (Vogel et al., 1982; Styan, 1998; Styan and Butler, 2000). This model incorporates both concentration and swimming speed of sperm as key determinants of fertilization success.

In the only study to date that has investigated the impacts of ocean acidification on fertilization kinetics, Havenhand et al. (2008) found statistically significant changes in sperm swimming speed and percent motility that, when translated into the fertilization kinetics model, predicted a $24.9 \%$ decrease in fertilization success. This corresponded closely with the 20.4-25.9\% decreases in fertilization success they observed in their experiments. They concluded that, for the urchin species they studied, ocean acidification-induced reductions in fertilization success were a result of the impacts of ocean acidification on sperm swimming behaviour.

More recent work (Havenhand et al., 2009) has shown that impacts of ocean acidification on fertilization success vary markedly, even between closely related species. Here we report the results of an investigation of the impacts of $\mathrm{CO}_{2}$-induced ocean acidification on the sperm swimming behaviour and fertilization kinetics of the Pacific oyster Crassostrea gigas. We specifically tested the hypothesis that nearfuture levels of ocean acidification $(\leq 0.4 \mathrm{pH}$ unit decrease) will not affect the sperm motility, sperm swimming speed, or fertilization success of Crassostrea gigas. We also provide statistical power analyses of non-significant results to address the key question of whether there were no biologically significant effects of $\mathrm{pH}$, or whether there were significant effects but that our experimental design was unable to detect these.

\section{Methods}

\subsection{General methods}

Individual $C$. gigas were collected on multiple occasions between 11 July 2008 and 6 August 2008 from a mixed mussel/oyster bed $\left(58^{\circ} 52.1^{\prime} \mathrm{N}, 11^{\circ} 09.4^{\prime} \mathrm{E}\right)$ close to the Tjärnö Marine Biological Laboratory, western Sweden. Individuals were held in flow-through surface sea water (mean $T^{\circ} \pm$ s.e. $=20.1 \pm 0.46^{\circ} \mathrm{C}$, salinity $=24.0 \pm 0.39 \%$, $\mathrm{pH}=8.15 \pm 0.01$, total alkalinity $=2.02$ [alkalinity measured at $5 \mathrm{~m}$ depth at SMHI station, Släggö]). Oysters were fed daily ad libitum with a mixture of microalgae (Shellfish Diet 1800 from Instant Algae ${ }^{\circledR}$ ).

This same seawater, filtered to $0.22 \mu \mathrm{m}$, (FSW) was used throughout for experiments. Acidified FSW was created by bubbling $\mathrm{CO}_{2}$ until a stable $\mathrm{pH}$ reduction of $\sim 0.35$ units from FSW pH had been obtained (Table 1). Bubbling was monitored manually and $\mathrm{pH}$ was measured using a benchtop $\mathrm{pH}-$ meter calibrated with NBS buffers. FSW was used as a control medium in all experiments.

Oysters were strip-spawned by drilling a hole through the shell above the gonads and pipetting out "dry" sperm and eggs. Sperm were held dry on ice to extend their lifespan. Eggs were held in FSW in a Petri-dish for $\sim 30 \mathrm{~min}$ before use. Experiments were conducted at $21-22^{\circ} \mathrm{C}$ as soon as possible after spawning.

Sperm suspensions were generated by diluting $1-5 \mu \mathrm{l}$ dry sperm (depending on concentration) from a single male oyster into $1-2 \mathrm{ml}$ of $\mathrm{pH} 8.15$ or $\mathrm{pH} 7.8 \mathrm{FSW}$ immediately before use. Dilutions generated $10^{3}-10^{4}$ sperm. $\mu \mathrm{l}^{-1}$ which prior experiments had shown to be optimal for sperm motility assessment. A small drop $(\approx 100 \mu \mathrm{l})$ of this sperm suspension was placed on an albumin-coated microscope slide and a cover-slip, which were separated by a $0.75 \mathrm{~mm}$ thick O-ring to minimise wall effects on sperm swimming speed (Havenhand et al., 2008). Sperm behaviour was then recorded onto DV-tape at 25 frames s$^{-1}$ using an inverted compound microscope (Leica ${ }^{\odot}$ DM-IL, 10 $\times$ objective) and digital video camera (Sony 3CCD ExwaveHD). All recordings were made within 10s of the sperm suspension being placed on the slide. Preliminary trials showed that the $\mathrm{pH}$ of this drop of sperm suspension did not significantly change over this period: mean $\Delta \mathrm{pH} \pm$ s.e. after $100 \mathrm{~s}$ was $-0.010 \pm 0.005 \mathrm{pH}$ units). For each male, ten replicate observations (slides) were made for 10 individually prepared sperm suspensions in each of FSW or acidified FSW (Table 1). Video was post-processed with Final Cut Pro ${ }^{\circledR}$ (Apple Computer, Cupertino, CA), and $1 \mathrm{~s}$ video clips from each slide (replicate) were analyzed using CellTrak1.3 ${ }^{\circledR}$ (Motion Analysis Corporation, Santa Rosa, CA). Average sperm speed and percentage of motile sperm was determined for each slide. This process was repeated for each of 16 different males. 
Table 1. Sperm swimming behaviour in FSW and acidified FSW (acFSW). Speed=speed of motile sperm (i.e. $>15 \mu \mathrm{m} / \mathrm{s})$; $P(T<=t)$ two tail ( $\mathrm{df}=18$ in all cases), $\mathrm{P} \leq 0.05$ marked in bold italics. Separate dates signify different single males. Grey text indicates experiments where only motility data are available, black text indicates experiments with motility and fertilization data (cf. Table 2).

\begin{tabular}{|c|c|c|c|c|c|c|c|c|c|c|c|c|c|}
\hline Date & Trial & Salinity & $\begin{array}{l}\text { pH } \\
\text { FSW }\end{array}$ & $\begin{array}{c}\mathrm{pH} \\
\mathrm{acFSW}\end{array}$ & $\Delta \mathrm{pH}$ & \begin{tabular}{|l|} 
Speed \\
FSW
\end{tabular} & $\begin{array}{l}\text { Speed } \\
\text { acFSW }\end{array}$ & $\Delta$ Speed & $P$ & $\begin{array}{c}\% \text { motile } \\
\text { FSW }\end{array}$ & $\begin{array}{c}\% \text { motile } \\
\text { acFSW }\end{array}$ & $\Delta$ Motile & $P$ \\
\hline 30.07 .2008 & & 25.2 & 8.16 & 7.81 & -0.35 & 102.3 & 98.2 & -4.08 & 0.266 & 77.8 & 79.2 & 1.38 & 0.146 \\
\hline 31.07 .2008 & & 21.4 & 8.16 & 7.81 & -0.35 & 107.5 & 117.6 & 10.19 & $<0.001$ & 71.8 & 69.4 & -2.32 & 0.030 \\
\hline 04.08 .2008 & $E$ & 22.4 & 8.21 & 7.81 & -0.39 & 78.8 & 65.7 & -13.13 & 0.004 & 62.0 & 56.6 & $\begin{array}{l}-5.33 \\
\end{array}$ & 0.314 \\
\hline 05.08 .2008 & $\mathrm{~F}$ & 22.5 & 8.16 & 7.83 & -0.33 & 61.7 & 62.8 & 1.12 & 0.621 & 30.4 & 27.0 & -3.44 & 0.397 \\
\hline 06.08 .2008 & $G$ & 24.7 & 8.13 & 7.85 & -0.28 & 82.1 & 69.7 & -12.42 & 0.027 & 59.9 & 48.6 & -11.33 & 0.498 \\
\hline 07.08 .2008 & & 22.2 & 8.14 & 7.82 & -0.32 & 57.8 & 67.9 & 10.17 & 0.135 & 28.1 & 29.3 & 1.20 & 0.115 \\
\hline 11.08 .2008 & $\mathrm{H}$ & 23.7 & 8.16 & 7.81 & -0.35 & 81.8 & 78.7 & -3.09 & 0.547 & 43.9 & 40.9 & -3.02 & 0.269 \\
\hline 13.08 .2008 & 1 & 25.9 & 8.13 & 7.82 & -0.31 & 72.6 & 81.1 & 8.50 & 0.043 & 48.8 & 56.6 & 7.81 & 0.911 \\
\hline 14.08 .2008 & $\mathrm{~J}$ & 26.1 & 8.08 & 7.86 & -0.22 & 102.7 & 111.7 & 9.00 & 0.001 & 46.9 & 50.4 & 3.58 & 0.494 \\
\hline 15.08 .2008 & $\mathrm{~K}$ & 25.8 & 8.09 & 7.81 & -0.28 & 103.4 & 125.8 & 22.38 & $<0.001$ & 57.1 & 69.1 & 11.98 & 0.258 \\
\hline 16.08 .2008 & L & 25.9 & 8.09 & 7.81 & -0.28 & 113.3 & 122.9 & 9.63 & 0.025 & 60.7 & 60.0 & -0.74 & 0.598 \\
\hline 18.08 .2008 & $M$ & 26.7 & 8.16 & 7.84 & -0.32 & 82.5 & 83.9 & 1.39 & 0.690 & 59.1 & 52.2 & -6.89 & 0.774 \\
\hline 19.08 .2008 & $\mathrm{~N}$ & 22.1 & 8.12 & 7.82 & -0.30 & 100.8 & 104.2 & 3.44 & 0.490 & 65.1 & 72.9 & 7.80 & 0.017 \\
\hline 20.08 .2008 & $\mathrm{O}$ & 23.9 & 8.18 & 7.80 & -0.38 & 94.0 & 97.6 & 3.59 & 0.530 & 36.4 & 38.9 & 2.44 & 0.511 \\
\hline 21.08 .2008 & $\mathrm{P}$ & 24.1 & 8.18 & 7.80 & -0.38 & 126.7 & 124.2 & -2.46 & 0.815 & 69.2 & 65.4 & -3.78 & 0.169 \\
\hline 22.08 .2008 & $Q$ & 24.0 & 8.24 & 7.81 & -0.43 & 105.8 & 97.5 & -8.27 & 0.130 & 67.0 & 61.4 & -5.61 & 0.257 \\
\hline Mean & & 24.20 & 8.15 & 7.82 & -0.33 & 92.10 & 94.30 & 2.25 & & 55.30 & 54.90 & -0.39 & \\
\hline s.e. & & 0.42 & 0.01 & 0.00 & 0.01 & 4.77 & 5.52 & 2.35 & & 3.70 & 3.80 & 1.53 & \\
\hline
\end{tabular}

For fertilization success experiments, eggs were extracted from three or more female oysters and mixed with sperm from one male (where possible these were the same males for which motility data were obtained; Tables 1,2). Mixed batches of eggs were used to minimize sperm-egg incompatibilities. Fertilization protocols followed those used by Havenhand et al. (2008). Briefly, fertilizations were carried out in filter-dishes $(25 \mathrm{~mm} \emptyset \times 20 \mathrm{~mm} \mathrm{H}, 20 \mu \mathrm{m}$ mesh floor $)$ placed in each well of two 6-well plates. Wells were filled with $5 \mathrm{ml}$ of FSW or acidified FSW (Table 2). For each $\mathrm{pH}$, a 6-step, 6-fold sperm dilution series was then created. Sperm concentrations were checked post-hoc by haemocytometer counts. An aliquot of $50 \mu \mathrm{l}$ of egg suspension (5002000 eggs, depending on concentration) was added to each filter dish and then transferred to the sperm suspension and left for $12 \mathrm{~min}$. Sperm were subsequently removed from the eggs by rinsing the filter dishes with FSW or acidified FSW. Eggs were then transferred to new 6-well plates containing FSW or acidified FSW. Fertilization success rate (percentage of fertilized eggs) was determined after $\sim 1 \mathrm{~h}$ by directly enumerating the proportion of 200 eggs that showed a polar-body or cleavage.

\subsection{Data analysis}

Before statistical analysis all percentage data were arc-sin transformed to meet the assumption of normality, which was subsequently checked by inspection of box-plots (Quinn and Keough, 2002). The assumption of homogeneity of variance among subgroups (different males, treatments, etc.) was as- sessed using Levene's test. No significant differences among variances of subgroups were found.

Effects of $\mathrm{pH}$ on swimming speed and percent motility of sperm for individual males were assessed by $t$ test using SPSSTM. Effects of $\mathrm{pH}$ on swimming speed and percent motility of sperm across all males were assessed by two-factor mixed-model ANOVA (pH=fixed, date/male=random), again using SPSS ${ }^{\mathrm{TM}}$. The power of our experiments (the likelihood that our tests would have detected a biologically meaningful effect had it existed) was determined by power analysis using the program G*Power (http://www.psycho.uni-duesseldorf.de/ abteilungen/aap/gpower3/).

\section{Results}

Mean sperm swimming speeds were very similar at both $\mathrm{pH}$ levels (mean \pm s.e. for $\mathrm{pH} 8.15=92.1 \pm 4.8 \mu \mathrm{m} \mathrm{s}^{-1}$, $\mathrm{pH}$ $7.8=94.3 \pm 5.5 \mu \mathrm{m} \mathrm{s}^{-1}$, Table 1). Similarly, there was a very small effect of $\mathrm{pH}$ on mean percent motility of sperm (mean \pm s.e. for $\mathrm{pH} 8.15=55.3 \pm 3.7 \%$ and for pH 7.8 $=54.9 \pm 3.8 \%$, Table 1). These differences were not statistically significant (ANOVA sperm speed, $F_{1,15}=0.911$, $P=0.355$; percent motility, $F_{1,15}=0.376, P=0.549$ ). Power analysis showed that these tests had $>80 \%$ power to detect a $5 \%$ change in percent motility.

Highly significant positive and negative effects of $\mathrm{pH}$ on sperm swimming speed were observed in some individual males, and two significant effects on sperm motility were observed ( $t$-test, Table 1). Most males showed non-significant 
Table 2. Fertilization success in FSW and acidified FSW (acFSW). FSR max $=$ maximum Fertilization Success Rate. $S_{\max }$ indicates sperm concentration that yielded FSR $\max$. Separate dates signify different single males. Grey text indicates experiments where only fertilization data are available, black text indicates experiments with motility and fertilization data (cf. Table 1).

\begin{tabular}{|c|c|c|c|c|c|c|c|c|c|c|}
\hline Date & Trial & $\begin{array}{l}\text { pH } \\
\text { FSW }\end{array}$ & $\begin{array}{c}\text { pH } \\
\text { acFSW }\end{array}$ & $\Delta p H$ & \# females & $\begin{array}{l}\text { FSR }_{\max } \\
\text { FSW }\end{array}$ & $\begin{array}{l}\text { FSR }_{\max } \\
\text { acFSW }\end{array}$ & $\Delta \mathrm{FSR}_{\max }$ & $\begin{array}{c}S_{\max } \text { FSW } \\
\left(\text { sperm. }\left.\mu\right|^{-1}\right)\end{array}$ & $\begin{array}{l}S_{\max } \text { acFSW } \\
\left(\text { sperm. } \text { l }^{-1} \text { ) }\right.\end{array}$ \\
\hline 21.07 .2008 & A & 8.19 & 7.78 & -0.41 & 3 & 86.0 & 84.0 & 2.0 & 7,700 & 7,700 \\
\hline 22.07 .2008 & $B$ & 8.19 & 7.78 & -0.41 & 4 & 82.0 & 88.0 & -6.0 & 1,400 & 1,400 \\
\hline 23.07 .2008 & $C$ & 8.13 & 7.85 & -0.28 & 5 & 89.0 & 91.0 & -2.0 & 9,900 & 1,700 \\
\hline 24.07 .2008 & $\mathrm{D}$ & 8.14 & 7.82 & -0.32 & 3 & 92.0 & 88.0 & 4.0 & 11,700 & 1,900 \\
\hline 04.08 .2008 & $\mathrm{E}$ & 8.21 & 7.81 & -0.39 & 4 & 71.0 & 60.0 & 11.0 & 3,500 & 5,800 \\
\hline 05.08 .2008 & $\mathrm{~F}$ & 8.16 & 7.83 & -0.33 & 4 & 55.0 & 53.0 & 2.0 & 6,200 & 6,200 \\
\hline 06.08 .2008 & $\mathrm{G}$ & 8.13 & 7.85 & -0.28 & 3 & 56.0 & 59.0 & -3.0 & 30,000 & 30,000 \\
\hline 11.08 .2008 & $\mathrm{H}$ & 8.16 & 7.81 & -0.35 & 3 & 37.0 & 46.0 & -9.0 & 10,100 & 10,100 \\
\hline 13.08 .2008 & I & 8.13 & 7.82 & -0.31 & 5 & 29.0 & 34.0 & -5.0 & 6,900 & 6,900 \\
\hline 14.08 .2008 & $\mathrm{~J}$ & 8.08 & 7.86 & -0.22 & 3 & 60.0 & 59.0 & 1.0 & 33,300 & 33,300 \\
\hline 15.08 .2008 & $\mathrm{~K}$ & 8.09 & 7.81 & -0.28 & 3 & 58.0 & 66.0 & -8.0 & 9,600 & 9,600 \\
\hline 16.08 .2008 & $\mathrm{~L}$ & 8.09 & 7.81 & -0.28 & 3 & 63.0 & 60.0 & 3.0 & 11,600 & 11,600 \\
\hline 18.08 .2008 & $M$ & 8.16 & 7.84 & -0.32 & 3 & 59.0 & 60.0 & -1.0 & 20,300 & 20,300 \\
\hline 19.08 .2008 & $\mathrm{~N}$ & 8.12 & 7.82 & -0.30 & 3 & 65.0 & 64.0 & 1.0 & 3,500 & 3,500 \\
\hline 20.08 .2008 & 0 & 8.18 & 7.80 & -0.38 & 3 & 57.0 & 60.0 & -3.0 & 4,900 & 4,900 \\
\hline 21.08 .2008 & $P$ & 8.18 & 7.80 & -0.38 & 3 & 55.0 & 54.0 & 1.0 & 3,400 & 20,300 \\
\hline 22.08 .2008 & $\mathrm{Q}$ & 8.24 & 7.81 & -0.43 & 1 & 71.0 & 76.0 & -5.0 & 11,800 & 11,800 \\
\hline Mean & & 8.15 & 7.82 & -0.33 & & 63.38 & 64.13 & -0.75 & 10,864 & 10,941 \\
\hline s.e. & & 0.01 & 0.01 & 0.01 & & 4.36 & 4.00 & 1.25 & 2,329 & 2,473 \\
\hline
\end{tabular}

results. Power analyses were not conducted for individual males.

Mean fertilization success in $\mathrm{pH} 8.15$ was similar to that in $\mathrm{pH} 7.8$ (63.4\% and $64.1 \%$ respectively, Table 1$)$. Correspondingly, the fertilization kinetics curves (Fig. 1) showed remarkable similarity between the treatments and replicates. The sperm concentration at which maximum fertilization was observed, $S_{\max }$, did not differ markedly with pH (10 864 and 10941 sperm. $\mu \mathrm{l}^{-1}$ in $\mathrm{pH} 8.15$ and $\mathrm{pH} 7.8$, respectively, Table 1). These differences were not statistically significant (ANOVA FSR max $_{\max }, F_{1,12}=0.014, P=0.909$; ANOVA $S_{\max }$, $F_{1,12}=0.631, P=0.442$ ). Power analysis showed that these tests had $>80 \%$ power to detect a change of $4.5 \%$ in maximum fertilization success $\left(\mathrm{FSR}_{\max }\right)$.

\section{Discussion}

The absence of significant overall effects of $\mathrm{pH}$ on sperm swimming behaviour and fertilization success is remarkable (Fig. 1, Tables 1, 2). Power analyses showed clearly that these results were not due to inadequate statistical power: our analyses had a high probability of detecting quite subtle effects of $\mathrm{pH}$ ( $5 \%$ change in response) - levels far lower than those reported for other species (Kurihara and Shirayama, 2004; Havenhand et al., 2008). This is an important result that allows us to conclude that the absence of significant effect is likely a true reflection of the responses of Crassostrea gigas gametes and zygotes from the Swedish west coast to levels of $\mathrm{CO}_{2}$-induced acidification expected by the end of this century (Caldeira and Wickett, 2003; Blackford and Gilbert, 2007), rather than a result of low statistical power caused by excessive variation or inadequate replication.

Kurihara et al. (2007) also found no effect of $\mathrm{CO}_{2}$-induced acidification (to $\mathrm{pH} 7.4$ ) on fertilization in $C$. gigas from Japan. Those authors did not include a power analysis of their data, and it is not possible to reconstruct this from the data they provide. The variance in their data was, however, substantial (their Fig. 1) indicating that they may have lacked sufficient power to detect a subtle effects of $\mathrm{pH}$ at this stage of the life-cycle. Consequently it is difficult to place these results in context with the work presented here.

Other work by Kurihara's group has shown that after just $24 \mathrm{~h}$, the larval stages of $C$. gigas are negatively impacted by $\mathrm{CO}_{2}$-induced acidification at $\mathrm{pH}$ levels equivalent to those used here (Kurihara, 2008). This suggests that although fertilization success and early embryogenesis in this species are unlikely to be impacted by near-future levels of ocean acidification, actively calcifying larvae are more susceptible to such decreases in $\mathrm{pH}$.

We observed variation in the response of sperm swimming behaviour to acidification that was statistically significant in 7 of 16 males (Table 1). It is tempting to suggest that this could be evidence for variable adaptive capacity of male $C$. gigas to respond to ocean acidification. If 

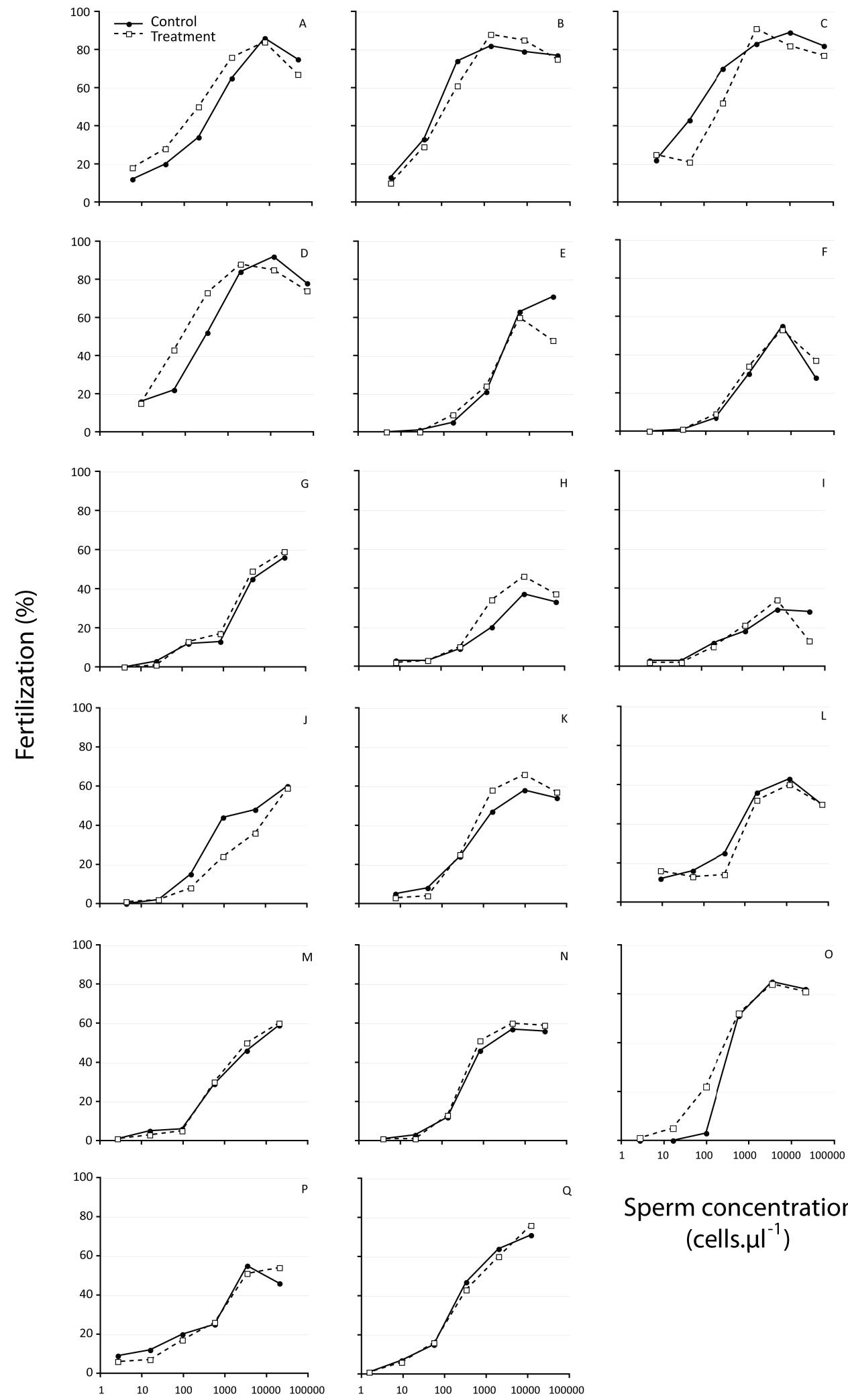

\section{Sperm concentration \\ (cells. $\mu^{-1}$ )}

Fig. 1. Fertilization success and sperm concentration in "Control" (pH 8.15) and "Treatment" (pH 7.8) water. See Tables 1,2 for key to males/dates and $\mathrm{pH}$ conditions. 
so, we would predict that the observed changes in sperm swimming behaviour would be reflected in the fertilization success of those males (i.e. males whose sperm swam faster at low $\mathrm{pH}$ should have correspondingly higher fertilization success and vice versa). At the sperm concentrations we used to assess motility $\left(10^{3}-10^{4}\right.$ sperm. $\left.\mu \mathrm{l}^{-1}\right)$, proportional changes in swimming behaviour translate almost directly in the fertilization kinetics model (Styan, 1998) to effects on fertilization success (i.e. a $20 \%$ increase in swimming speed generates a $\sim 20 \%$ increase in predicted fertilization success). This should be reflected in a significant positive linear relationship between changes in sperm swimming speed ( $\Delta$ speed, Table 1$)$ and changes in $\mathrm{FSR}_{\max }\left(\Delta \mathrm{FSR}_{\max }\right.$, Table 2$)$. The relationship between these two variables was in fact non-significant and negative $\left(\Delta \mathrm{FSR}_{\max }=-0.18 \Delta\right.$ speed $-0.88, n=13, r^{2}=0.112$, $P=0.264)$. Therefore it seems likely that the variability in responses of $C$. gigas sperm swimming to $\mathrm{pH}$ seen here do not translate into measurable differences in fertilization success. This result contrasts with the only comparable available data for sea urchins, where significant $\mathrm{CO}_{2}$-induced reductions in sperm swimming behaviour were reflected in similar reductions in fertilization (Havenhand et al., 2008).

To our knowledge this is the first report of repeated assessment of the impacts of ocean acidification on a species from different ocean basins. This is an important step, and further extension to the geographic spread of sampling locations will greatly enhance our ability to extrapolate results from one location into a global context. Similarly, if we are to understand and predict the full consequences of OA on marine organisms, our experiments need sufficient statistical power to detect biologically meaningful effects - i.e. maximise the likelihood that non-significant results are a reflection of no biological effect, and minimise the likelihood that such results are caused by insufficient replication for the levels of variation present in the experimental system. In this context, confirming the likely absence of significant impact of OA on a given species and process is every bit as important as finding significant effects (negative or positive).

Acknowledgements. We'd like to thank Elin Renborg for valuable discussions, constructive comments, and excellent assistance in the laboratory and Sam Dupont (University of Gothenburg), Gerry Quinn (Deakin University) and Mike Thorndyke (Royal Swedish Academy of Sciences) for valuable discussions during the planning of this work. This work was performed within the Linnaeus Centre for Marine Evolutionary Biology at the University of Gothenburg (http://www.cemeb.science.gu.se/), supported by a Linnaeus-grant from the Swedish Research Councils VR and Formas and Formas grant 2008-637 to JNH and M. Thorndyke, and is a contribution to the "European Project on Ocean Acidification" (EPOCA) which received funding from the European Community's Seventh Framework Programme (FP7/2007-2013) under grant agreement no. 211384.

Edited by: T. Trull

\section{References}

Blackford, J. C., and Gilbert, F. J.: pH variability and $\mathrm{CO}_{2}$ induced acidification in the North Sea, Journal of Marine Systems, 64, 229-241, 2007.

Caldeira, K. and Wickett, M. E.: Anthropogenic carbon and ocean pH, Nature, 425, 365-365, 2003.

Cowen, R. K., Lwiza, K. M. M., Sponaugle, S., Paris, C. B., and Olson, D. B.: Connectivity of marine populations: Open or closed?, Science, 287, 857-859, 2000.

Doney, S. C., Fabry, V. J., Feely, R. A., and Kleypas, J. A.: Ocean Acidification: The other $\mathrm{CO}_{2}$ problem, Annu. Rev. Mar. Sci., 1, 169-192, 2009.

Fabry, V. J., Seibel, B. A., Feely, R. A., and Orr, J. C.: Impacts of ocean acidification on marine fauna and ecosystem processes, ICES J. Mar. Sci., 65, 414-432, doi:10.1093/icesjms/fsn048, 2008.

Feely, R. A., Sabine, C. L., Hernandez-Ayon, J. M., Ianson, D., and Hales, B.: Evidence for upwelling of corrosive "acidified" water onto the continental shelf, Science, 320, 1490-1492, 2008.

Harley, C. D. G., Hughes, A. R., Hultgren, K. M., Miner, B. G., Sorte, C. J. B., Thornber, C. S., Rodriguez, L. F., Tomanek, L., and Williams, S. L.: The impacts of climate change in coastal marine systems, Ecol. Lett., 9, 228-241, 2006.

Havenhand, J. N., Buttler, F. R., Thorndyke, M. C., and Williamson, J. E.: Near-future levels of ocean acidification reduce fertilization success in a sea urchin, Current Biol., 18, R651-R652, 2008.

Havenhand, J. N., Renborg, E., Williamson, J. E., and Mifsud, S.: Near-future levels of ocean acidification have varying effects on fertilization success in closely related marine invertebrates, in preparation, 2009.

IPCC: Climate Change 2007: The Physical Science Basis. Contribution of Working Group I to the Fourth Assessment Report of the Intergovernmental Panel on Climate Change, edited by: Solomon, S., Qin, D., Manning, M., Chen, Z., Marquis, M., Averyt, K. B., Tignor. M., and Miller, H. L., CUP, Cambridge, 2007.

Kurihara, $\mathrm{H}$.: Effects of $\mathrm{CO}_{2}$-driven ocean acidification on the early developmental stages of invertebrates, Mar. Ecol.-Prog. Ser., 373, 275-284, doi:10.3354/meps07802, 2008.

Kurihara, H., Asai, T., Kato, S., and Ishimatsu, A.: Effects of elevated $\mathrm{pCO}_{2}$ on early development in the mussel Mytilus galloprovincialis, Aquat. Biol., 4, 225-233, doi:10.3354/ab00109, 2009.

Kurihara, H., Kato, S., and Ishimatsu, A.: Effects of increased seawater $\mathrm{pCO}_{2}$ on early development of the oyster Crassostrea gigas, Aquat. Biol., 1, 91-98, 2007.

Kurihara, H. and Shirayama, Y.: Effects of increased atmospheric $\mathrm{CO}_{2}$ on sea urchin early development, Mar. Ecol.-Prog. Ser., 274, 161-169, 2004.

Pechenik, J. A.: On the advantages and disadvantages of larval stages in benthic marine invertebrate life cycles, Mar. Ecol.-Prog. Ser., 177, 269-297, 1999.

Quinn, G. and Keough, M.: Experimental design and data analysis for biologists, Cambridge University Press, 538 pp., 2002.

Raven, J., Caldeira, K., Elderfield, H., Hoegh-Guldberg, O., Liss, P., Riebesell, U., Shepherd, J., Turley, C., and Watson, A. Ocean acidification due to increasing atmospheric carbon dioxide, Royal Society, London, 57 pp., 2005.

Styan, C. A.: Polyspermy, egg size, and the fertilization kinetics of free-spawning marine invertebrates, Am. Nat., 152, 290-297, 
1998.

Styan, C. A. and Butler, A. J.: Fitting fertilisation kinetics models for free-spawning marine invertebrates, Mar. Biol., 137, $943-$ 951, 2000.

Styan, C. A., Kupriyanova, E., and Havenhand, J. N.: Barriers to cross-fertilization between populations of a widely dispersed polychaete species are unlikely to have arisen through gametic compatibility arms-races, Evolution, 62, 3041-3055, 2008.
Vogel, H., Czihak, G., Chang, P., and Wolf, W.: Fertilization kinetics of sea urchin eggs, Math. Biosci., 58, 189-216, 1982.

Widdicombe, S. and Spicer, J. I.: Predicting the impact of ocean acidification on benthic biodiversity: What can animal physiology tell us?, J. Exp. Mar. Biol. Ecol., 366, 187-197, doi:10.1016/j.jembe.2008.07.024, 2008. 